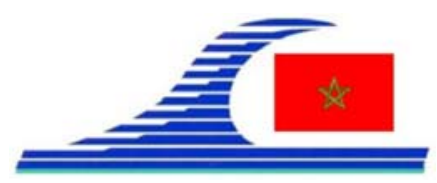

\author{
Conférence Méditerranéenne Côtière et Maritime \\ EDITION 2, TANGER, MAROC (2011) \\ Coastal and Maritime Mediterranean Conference \\ Disponible en ligne - http://www.paralia.fr - Available online
}

\title{
Two coast projects in France: off shore wind turbines vibrations under waves load
}

\author{
Laurent DELABY ${ }^{1}$, Olivier BLANCHARD ${ }^{1}$, \\ Renaud LABORBE ${ }^{2}$, Jérôme CUNY ${ }^{2}$
}

\author{
1. I.C. Ingénieurs Conseils, 143 Bd de Magenta, 75010 Paris, France. \\ l.delaby@yahoo.fr; http://www.ic-ingenieursconseils.fr/ \\ 2. Open Ocean, 18 rue Yves Toudic 75010 Paris, France, \\ contact@openocean.fr; http://www.openocean.fr/
}

\begin{abstract}
:
Vibration analysis of a wind turbine system establishes a main natural frequency of $4.23 \mathrm{~s}$. This main frequency is close to ocean surface wave frequency in the windy Picardie region, north of France. This region has been selected by the French government to host one of the biggest offshore wind farm named the "Two-coast project". A brief study of marine conditions in this area provided us with numerical data to compute typical wave loading to be applied to the wind turbine system. Our finite element study evaluates the stress of the wave loading to be around $36 \mathrm{MPa}$ in the mast. Within these conditions, a wind turbine remains under steel elastic limit up to $200 \mathrm{MPa}$ However wind and tide level impact should now be taken into account for a complete study.
\end{abstract}

\section{Keywords:}

Off shore wind turbines - Wind energy - Vibration modeling - Numerical method oscillations - Vibratory stressing

\section{Introduction}

The main purpose of this paper is to estimate dynamics vibrations effects of wave load on a $5 \mathrm{MW}$ RE Power Wind offshore wind turbine to improve the conception of more resistant machines.

After defining threshold values from materials resistance, the vibration modeling leads us to calculate stress and deformations in the machine mast with a finite element method. This method enabled us to define threshold values in terms of vibration velocity in $\mathrm{mm} / \mathrm{s}$ and vibration acceleration in $\mathrm{m} / \mathrm{s}^{2}$ for the drive train components (generator, gear, and main bearing) and for the nacelle/ tower. The threshold values are defined as component-specific frequency bands.

Offshore wind turbines have specific differences compared to land wind turbines: they are under both wind solicitations and ocean wave solicitations. Thus, the frequency range of external load is wider for offshore machines than for onshore machines. In this paper, we focus specifically on wave analysis with force distribution and frequencies, 
La connaissance de la Mer :

un vecteur du développement durable en Méditerranée

and dynamical response of the offshore machine. These results are compared to the maritime conditions in the area of the Two-Coast offshore wind turbine project along the northern coast of France, to check if machines in this area would be under an excessive amount of stress.

\section{RE Power Wind offshore wind turbine modeling}

Steepness $k$ obtained by finite element discretization of the steel-mast (figure 1):

$k=\frac{F}{\Delta x}=\frac{10000}{1.3 \times 10^{-2}}=769231 \mathrm{~N} / \mathrm{m}$

with:

$$
\begin{aligned}
M & =m_{\text {rotor }}+m_{\text {nacelle }}=350000 \mathrm{~kg} \\
\omega_{0} & =\sqrt{\frac{k}{M}}=1.48 \mathrm{rad} / \mathrm{s}
\end{aligned}
$$

Thus, resonance frequency and period are: $f=0.23 \mathrm{~Hz}, T=4.23 \mathrm{~s}$.

The resonance frequency of $0.23 \mathrm{~Hz}$ of the wind machine calculated by this one degree of freedom modeling is close to classic frequency of short waves.

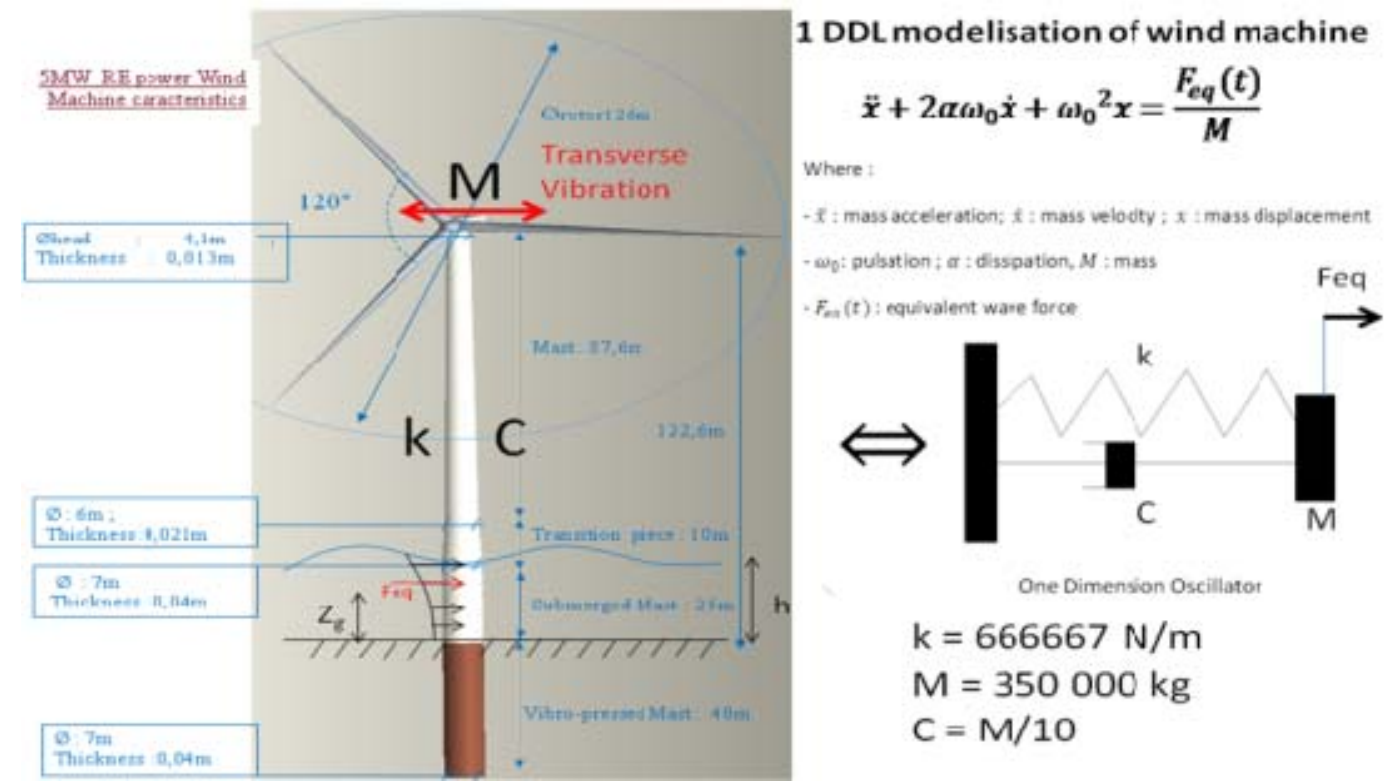

Figure 1. Principle of forced oscillation and wave loading modeling of the $5 M W R E$ Power Wind offshore wind turbine.

\section{Wave loading theoretical frame}

Wave loading is obtained from Morrison equation which gives an expression of force per unit length along the submerged cylindrical mast of the wind turbine machine. This formula is considered for each harmonic component of the sea wave state (adapted from BONNEFILLE, 1992): 


$$
F_{1}(\omega, z, t)=\frac{\rho \pi^{2} D H(\omega)}{2 T^{2}}\left(-C_{M} \pi \frac{D}{H(\omega)} E(z) \sin (\omega t) \pm C_{D} E(z)^{2} \cos ^{2}(\omega t)\right)
$$

with:

- $F_{1}(\omega, z, t)$ : force per unit length at $z$ depth, $0 \leq z \leq-h$

- $E(z)=\cosh (k(z+h)) / \sinh (k h) \quad$ and $+\operatorname{sign}$ when $-T / 4<t<T / 4$

- $\rho$ : water density;

- $\omega$ : wave harmonic component pulsation;

- $H(\omega)$ : elevation of wave harmonic component;

- $T=2 \pi / \omega$ : period of wave harmonic component;

- $\quad D$ : member width;

- $C_{M}$ : inertia coefficient obtained for Hs, Tp from Keulegan number (BURTON et al., 2011);

- $C_{D}$ : drag coefficient obtained for $H s, T p$ from Keulegan number (BURTON et al., 2011).

We calculate the resultant of this pressure by integration along the submerged structure.

$$
F_{e q}(\omega, t)=\int_{0}^{-h} F_{1}(\omega, z, t) d z
$$

And we estimate an equivalent level where we apply this resultant on the mast for each harmonic component (figure 1):

$$
z_{g}(\omega)=\frac{\int_{0}^{-h} z F_{1}(\omega, z, t) d z}{\int_{0}^{-h} F_{1}(\omega, z, t) d z}
$$

\section{Maritime conditions in Picardie (France)}

The Two-Coast project is one of the first offshore wind turbine to be launched in France. It will be built along the Picardie Coast in the northern part of France, the local depth is close to $25 \mathrm{~m}$ (see figure 2).
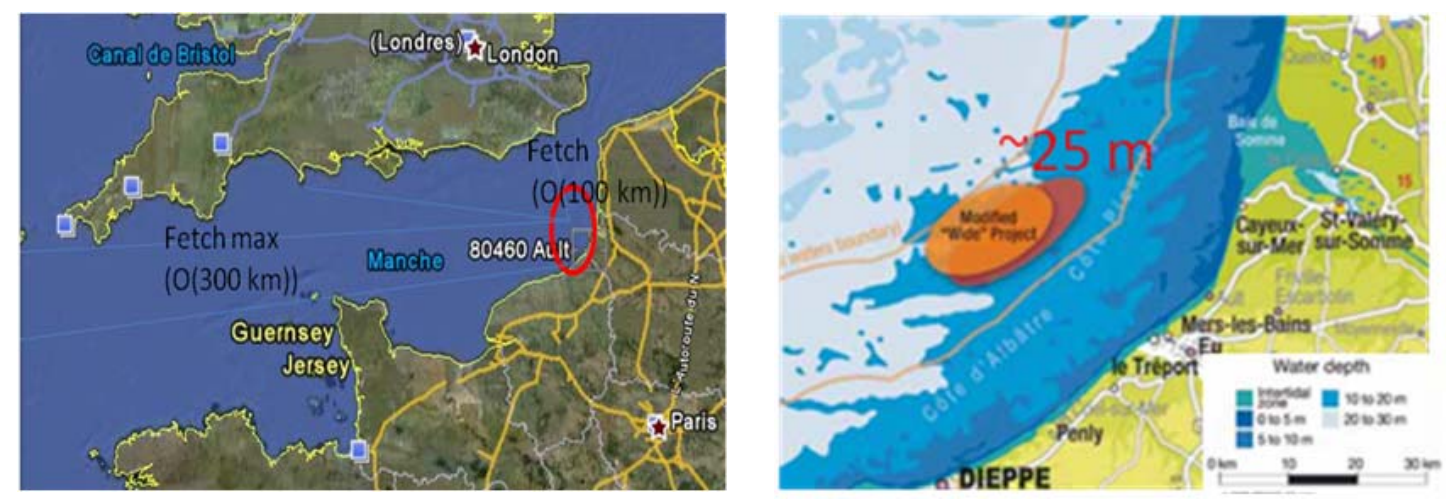

Figure 2. Left: Localization of the "Two Coast Project". Right: local bathymetry (adapted from LA COMPAGNIE DU VENT (2009)). 
La connaissance de la Mer :

un vecteur du développement durable en Méditerranée

Tidal amplitude is about $9 \mathrm{~m}$ in this area and waves are usually smaller than $1 \mathrm{~m}$ with short period around 4-6 s. Waves are exceptionally bigger than $5 \mathrm{~m}$ with period about $10 \mathrm{~s}$. The location of the Two-Coast project is protected from the biggest swell of the Atlantic by the Great Britain Island. Hence, it is only affected by waves generated across the Channel by the North Atlantic storms over a limited fetch $(<300 \mathrm{~km})$.
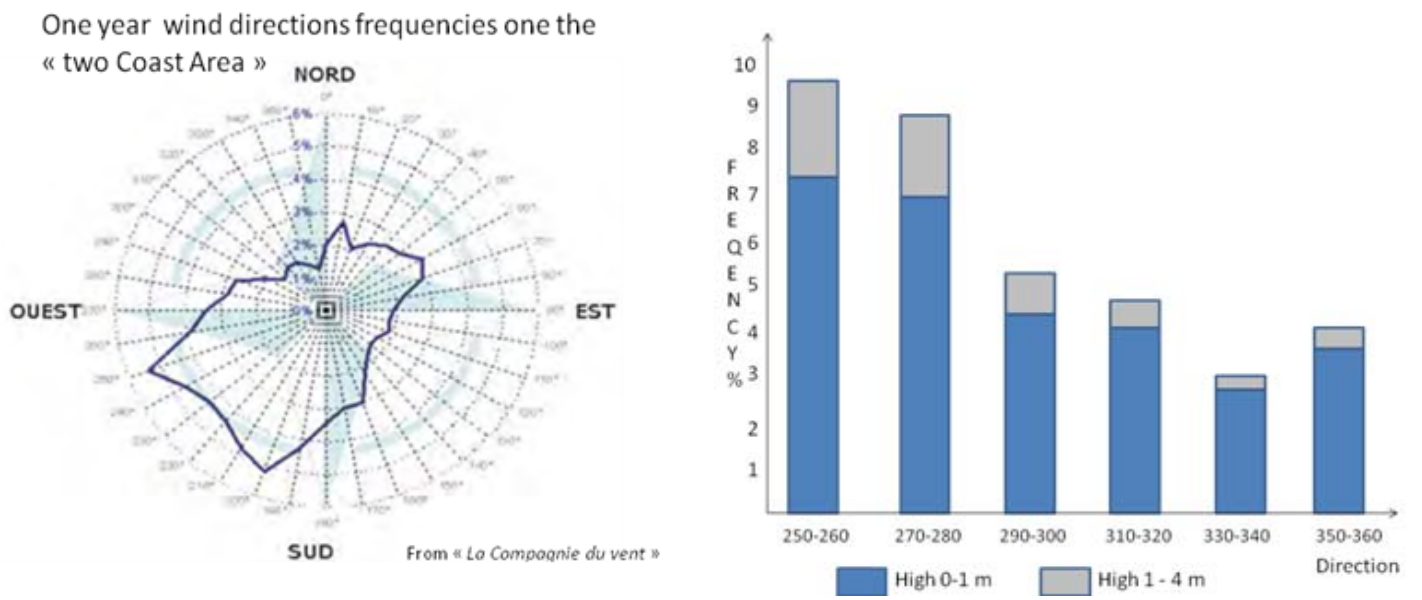

Figure 3. Left: Wind directions frequencies in the area of interest (LA COMPAGNIE DU VENT, 2009). Right: Wave heigth distribution with respect to direction (from) in open sea (1961-1993) off the Picardie coast, adapted from SOGREAH documents.

We note that the natural frequencies of the waves in the area of interest includes the frequency of the 5MW RE Power Wind wind turbine deduced from the 1-DDL model. Because of the limited fetch, we choose to use JONSWAP spectrum for constructing design waves loading with a 50 years and1 year return, and a "normal sea state" spectrum. We estimate sea-states from various sources, including the ANEMOC (web site) data base (COAST 2671 and COAST 3013 point). The gamma parameter is taken equal to 3.3 for each sea state.

Table 1. Values retained for Hs and Tp.

\begin{tabular}{llll}
\hline & "Classic storm" ( $>8 \%))$ & 1 year Storm (3\%) & 50 years storm $(0.05 \%)$ \\
\hline$H s(m)$ & 3 & 4 & 6.5 \\
$T p(s)$ & 8 & 10 & 12 \\
\hline
\end{tabular}

\section{Results (figure 4)}

A simulated water surface elevation time history is built from the JONSWAP spectrum. For the three types of conditions, we calculate the corresponding load time history from the Morrison equation and apply it in the one DDL motion equation which is solved by 
a finite-difference method. Maximum Von-Mises stress in the cylindrical steel mast is estimated by a finite element code from the maximum displacement of the mast head.

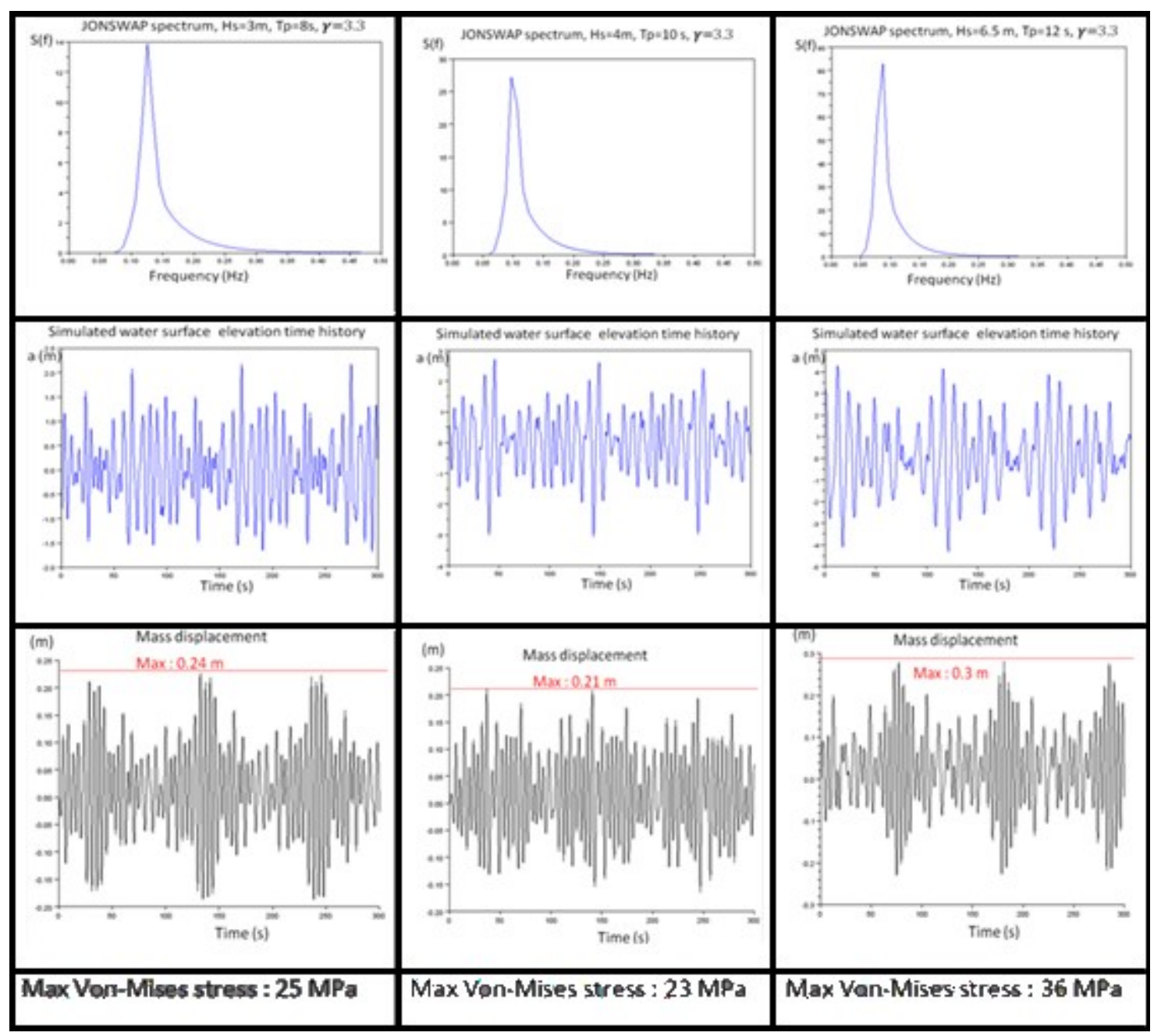

Figure 4. Up: Jonswap spectrum used for sea surface elevation reconstruction. Middle: Sea surface elevation history. Bottom: Head of the machine displacement. Max VonMises stress obtained from the head displacement in a quasi-static approximation.

\section{Conclusion}

Max Von-Mises stress remains under the steel elastic limit of about $200 \mathrm{MPa}$, hence suggesting that wind turbine are safe from an excessive wave stress along the Picardie Coast. However, we must not forget that only wave impact has been considered here.

\section{Perspectives}

A study including wind and waves conditions on different tide levels should now be performed to verify that the elastic conditions remains satisfactory. 
La connaissance de la Mer :

un vecteur du développement durable en Méditerranée

\section{References}

ANEMOC (web site). http://anemoc.cetmef.developpement-durable.gouv.fr/

BURTON T., JENKINS N., SHARPE D., BOSSANYI E., (2011). Wind Energy Handbook. Ed WILEY, second edition.

BONNEFILLE R. (1992). Cours d'hydraulique maritime. Masson, Paris.

LA COMPAGNIE DU VENT (2009). Projet de parc éolien en mer des 2 Côtes, Débat Public du 28 avril au 10 septembre 2010, Le Dossier du Maître d'Ouvrage. 120 p. 